quality. The line drawings adjacent to the photographs further clarify the points each plate illustrates. The author may remain amongst a minority of practitioners by preferring to introduce the fibreoptic bronchoscope via the rigid instrument or through an endotracheal tube, and preferably under general anaesthesia. However, the more commonly used routes with topical anaesthesia are very clearly discussed. The timely reminder that a bronchoscopist should be equally familiar with both the flexible and the rigid instruments is once again welcome. This book remains a richly informative work and should be compulsory reading for anybody wishing to become involved with bronchoscopy.

STEPHEN G. SPIRo

Brompton Hospital, London SW3 6HP.

\section{Family Planning; Fundamentals for Health Professionals}

By ANn CowPer and Cyril Young. Pp. 160, illustrated. Croom Helm, London, 1981. £11.95 (hardback) $£ 5.95$ (paperback).

The fundamentals of family planning are presented in this book in a basic and readable manner. It is orientated towards the provision of a service in the clinic situation and within the U.K., but does not emphasize sufficiently the importance of the team approach of all those working therein.

Although designed to cover the syllabus set for Course 900 of the Joint Board of Clinical Nursing Studies, it would be insufficient by itself adequately to equip postgraduate nurses to undertake delegation duties for doctors. Fortunately, the second stated aim of the authors, to stimulate interest in further reading, is fulfilled and a good bibliography is included for this purpose.

After dealing briefly with facilities for sex education and contraceptive advice in the first chapter, the next is devoted to 'Body Mechanics'. This is a simplified summary of relevant anatomy and physiology, supported by surprisingly old-fashioned illustrations.

Bearing in mind that the authors state that 'good family planning nurses ought not to be weighed down by facts inessential to good contraceptive practice', the excellent chapter on Infection of the Reproductive Organs would seem excessively detailed, especially concerning the medical treatment involved, for nurses. While unquestionably important, the length of this chapter and its early situation in the book creates a false impression of the frequency with which sexually transmitted disease is confronted in a family planning clinic.

After discussing clinic organization and cervical smear testing, at last the essential chapters are reached and deal with contraceptive methods, sterilization and unplanned pregnancy.

The description of the methods and their prescription are regrettably over-simplified and not always strictly accurate. The section on the use of injectables could be seriously misleading. There is little reference to the importance of risk/ benefit considerations, so important nowadays if methods are to be used without anxiety, and some controversial points are presented dogmatically without discussion or justification.

There is a most helpful chapter dealing with women with special needs including the young, the infertile, the older woman and those with psychosexual problems. The many and widespread ramifications of work in this field are thereby highlighted and the need for sensitive understanding of individuals stressed.

At $£ 5.95$ for a paperback this is an expensive book and is not sufficiently comprehensive for those doctors who intend to provide a contraceptive service. It would be useful, however, for some paramedical health professionals.

Barbara LAW

Whittington Hospital, London N19 5NF.

\section{Introduction to Clinical Pharmacology}

By M. J. EAdie, J. H. TYrer and F. Bochner, Pp. vi + 142, illustrated. M.T.P. Press Lancaster, 1981. £5.95.

This book aims to link preclinical and clinical studies in pharmacology and to introduce the principles which underlie rational drug use. The book begins with chapters on the passage of drugs through cell membranes and body fluids, drug action and receptors, biotransformation and the distribution of drugs. There then follow chapters on drug excretion, pharmacokinetics, interactions and adverse drug reactions and on drug dosage and its modification.

Although the intentions stated in the preface are admirable, the book fails to transmit enthusiasm for the subject and the authors have missed the opportunity to enliven the text with the sort of individual clinical case histories which would help emphasize the important points that they make.

R. M. Pearson

Dept of Clinical Pharmacology, St. Bartholomew's Medical College, London EC1A 7BE.

\section{Multiple Choice Questions in Pharmacology}

By R. W. Foster. Pp. xi+176. Butterworths, London, Boston, 1980. f3.50.

The Multiple Choice Questions (MCQ) technique has become part of the university scene, the students usually (being more adaptable?) accepting them in their stride with some dons less ready to assimilate this technique into examinations. Dons in medical schools where the emphasis is on classes of 150 to 250 students, however, see MCQs as an important device assisting students in testing their own knowledge and assisting staff to identify 'weak' students. Such 'weak' students can then be counselled and that scarce resource-academic tutoring-directed to 'salvaging' the weaker who are in danger of floundering or, worse still, foundering on the rocks in their academic course.

This slim volume entitled: ' 1200 Multiple Choice Questions in Pharmacology' is under the editorship of Dr R. W. Foster and distills the accumulated experience of many of the staff of the Department of Pharmacology, Materia Medica and Therapeutics in the University of Manchester.

In their Preface, the authors state that they offer a selection of MCQs in pharmacology which they hope may be found useful in four different ways, namely as a source of readymade questions for use by examiners; a source of ideas which may aid examiners in the construction of new questions; an aid to candidates in practising multiple choice examination technique; a means by which students can assess their own progress in acquiring pharmacological knowledge.

It is axiomatic that the setting of MCQs is a time-consuming process and the authors stress that they have debated, amended, tested and reviewed the responses to these questions over the last 6 years. It is only by constant review of the responses to MCQs that the stems and options can evolve to maximise discrimination.

Nine types of MCQ are defined clearly before the reader passes to the MCQs. In each section of the book, MCQs of the same type are grouped together so that the reader can 